(1986) Epidemic of AIDS-related virus (HTLV-III/LAV) infection among intravenous drug abusers. British Medical fournal 292, 527-9.

Salahuddin S. Z., Groopman J. E. \& Markham P. D. (1984) HTLV-III in symptom-free seronegative persons. Lancet ii, 1418-20.

\title{
Bystander resuscitation: is the public enthusiastic?
}

Sir

Bystander resuscitation schemes in operation in Seattle (USA) and Brighton (UK) have improved the outcome from sudden cardiac death (Eisenberg et al., 1979; Vincent et al., 1984).

Many UK hospitals are considering the introduction of bystander schemes. We have experienced some difficulty, with a small pilot scheme, in recruiting trainees from companies with First Aid or medical provision on site.

We have surveyed 879 adults living or working in the City of London to assess the likely response to the introduction of a City of London bystander resuscitation scheme; the results of our survey are shown in Table 1.

In recent years, emergency mobile coronary ambulances have been introduced in an attempt to reduce the death toll from sudden ventricular arrhythmias, often related to acute myocardial infarction (Sherman, 1979). Variable results have been reported following the introduction of such services. Poor results have been ascribed to the absence of efficient bystander resuscitation to support the victim until the arrival of the

Table 1 Survey of bystanders

\begin{tabular}{lcc}
\hline & Number & $\begin{array}{c}\text { Percentage of } \\
\text { total }\end{array}$ \\
\hline Questionnaires completed & 879 & 100 \\
& & \\
Questions relating to First Aid ability & 314 & $35 \cdot 7$ \\
Those who had previously attended a First Aid course & 202 & $22 \cdot 9$ \\
Those who had been taught external chest compression & 276 & $31 \cdot 3$ \\
Those who had been taught mouth-to-mouth ventilation & 246 & $27 \cdot 9$ \\
Those who had practised one, or both, of the above skills on a model & 16 & $0 \cdot 18$ \\
Those who had been re-tested in the previous one-year period & 213 & $24 \cdot 2$ \\
Those who would be prepared to attend a traditional 20-hour First & & $59 \cdot 1$ \\
Aid course & 520 & \\
Those who would be prepared to attend a 2-hour course, primarily & & \\
in BLS & & $31 \cdot 5$ \\
Questions relating to on-site First Aid/medical provision* & 289 & $22 \cdot 8$ \\
Those who had on-site provision of First Aider only & 200 & $26 \cdot 9$ \\
Those who had on-site provision of doctor, nurse and First Aider & 237 & \\
Those who had nothing & & \\
\hline
\end{tabular}

$*_{i}$.e. provided at their place of work. 
rescue service. To remedy this deficiency, bystander resuscitation schemes have been proposed and, in some instances, introduced. The success of these schemes must depend upon the skill of the course organisers and the enthusiasm of the general public It is encouraging that a significant proportion $(36 \%)$ of the City of London population have already had some training in First Aid, including the techniques of expired ait? respiration $(31 \%)$ and external chest compression $(23 \%)$. The lack of repeat trainingand testing $(0.2 \%)$ is disappointing, although predictable in view of the time taken ton complete a traditional First Aid course.

Voluntary First Aid organisations (for example, St John's Ambulance) have been⿳亠丷厂 extremely keen to be involved in our bystander resuscitation scheme. Basic life suppory (BLS) teaching can be provided in a 2-hour package and our survey shows that two thirds of the population would be willing to undertake this form of training. Bystanderw scheme training and traditional First Aid teaching are not mutually exclusive, indeed,,$\frac{\Phi}{\square}$ they are complementary, and we would hope that some people taught on bystande schemes may then wish to go on to further training on a full First Aid course run by ones of the voluntary organisations.

Our survey shows that $73 \%$ of employees have some medical or paramedicab provision on-site, including $22 \%$ who have on-site doctor, nurse and First Aider. This does not, however, satisfy the requirements of Seattle for one-third of the population top be trained in BLS and employers must be persuaded of this.

A successful bystander training scheme for BLS requires the cooperation of employers, a sufficient number of trainers, time for both training and re-training and the continued support of the general public.

DAVID V. SKINNER ${ }^{1}$, MARK WHITELEY ${ }^{2}$, STEPHEN MILES ${ }^{1} \&$ A. $\mathrm{CAMM}^{3}$

${ }^{1}$ Accident and Emergency Medicine Department, ${ }^{2}$ Medical Student and ${ }^{3}$ Departmen⿳亠口冋口 of Cardiology, St Bartholomew's Hospital, London, England

\section{REFERENCES}

Eisenberg M. S., Bergner L. \& Hallstrom A. (1979) Cardiac resuscitation in the community. fournal of the American Medical Association 241, 1095-7.

Sherman M. A. (1979) Mobile intensive care units: an evaluation of effectiveness. fournal of the Americani Medical Association 241, 1899-901.

Vincent R., Martin R., Williams G., Quinn E., Robertson G. \& Chamberlain D. A. (1984) A community scheme in cardiopulmonary resuscitation. British Medical fournal 288, 617-20.

\section{Asthma and thunderstorms}

Sir

The British Thoracic Association (1982) reported that more than 1500 people die each year in England and Wales from asthma, and that in excess of $80 \%$ were potentially preventable. With this in mind we feel that the following account of an influx of patients? 